\title{
Optical and Mechanical Properties of Diamond-Like Carbon Coatings Deposited by Filtered Cathodic Vacuum Arc Deposition
}

\author{
Yury M. Mironov ${ }^{1}$, Rodion O. Stepanov ${ }^{1}$, Alexey S. Osipkov ${ }^{1}$, Anna O. \\ Mironova ${ }^{2}$, Mstislav O. Makeev ${ }^{1}$, Pavel A. Mikhalev', and Nikolai S. Sedih ${ }^{2}$ \\ ${ }^{1}$ Bauman Moscow State Technical University, Moscow, Russia \\ ${ }^{2}$ New Plasma Technologies LLC, Moscow, Russia
}

Keywords: Filtered cathodic vacuum arc, diamond-like carbon, thin films, antireflective coating, microhardness.

\begin{abstract}
Diamond-like carbon (DLC) coating were deposited directly on glass, BaF2, MgF2, Si, Ge, PVC substrates by a FCVA deposition. The deposition process for DLC coating deposition on substrates was optimized. DLC films on different substrates were deposited to investigate mechanical and spectral characteristics. DLC coatings increased surface hardness. The spectral transmittance of the bare and coated substrates in the visible and IR region was measured. DLC layer thickness affects the optical transmittance of the coated substrate. This article is consider the problem of strengthening of optic materials used in the IR and visible spectrum by deposition of diamond like carbon coatings from FCVA method. Experimental studies showed that surface hardening of optical materials by deposition of diamond-like carbon coating improves optical and mechanical properties of these materials.
\end{abstract}

\section{Introduction}

Hard amorphous carbon coatings have attracted great research interest as protective optical or tribological coatings because of their unique combination of structural, topographic, mechanical and opto-electronic properties [1]. Technologically controlled deposition of diamond-like carbon coating with high amount of fractions of $\mathrm{sp} 3$ type $\mathrm{C}$ bonds allows to obtain attractive physical and mechanical properties for wide range of applications, such as hardening of optical windows, mechanical friction parts in automotive engine, gears, drivetrain components, drills, machinery tools, bearing parts, corrosion resistant elements, oil-gas pump, valve, bio-implants, etc. [2].

Optical materials (glass, optic soft crystals, semiconductors, polymer substrate) are often soft and hygroscopic; as a consequence they can be easily damaged during exploitation due to impact of atmospheric moisture, dust and various kinds of mechanical impact. Thus the surface hardening of this materials is important for achieve their high efficiency and durability.

One of important optical materials and industry widely used is transparent plastics and ITO films on glass, which are needed to be increased their surface hardness and wear resistance due to their surfaces are inherently soft and easily scratched or worn out in abrasive conditions, and thus the usage is limited to relatively mild service conditions. Additionally, an improvement optical properties and also anti-reflectivity is necessary for many optical applications. Most attractive coating for this purposes with abrasion-resistant and antireflection properties as known is diamondlike carbon coating [3].

Furthermore, important point of this work is develop the industry oriented deposition method to produce the DLC coatings that are homogeneous down to the nanometre level and that have smooth and dense surfaces.

Diamond-like carbon coatings can be prepared by a variety of methods, such as RF plasma enhanced CVD, cathodic-arc deposition, magnetron sputtering, pulsed laser ablation, etc. Their properties significantly varies depending on $\mathrm{sp} 2 / \mathrm{sp} 3$ ratio, content of hydrogen, adhesion, smoothness, compressive stresses. It is now well known that the hydrogen-free diamond-like carbon coating can deposited for wide range of optical materials with good appropriate properties by the filtered cathodic vacuum arc process (FCVA). Cathodic arc plasmas are characterized by a very 
high degree of ionization, with multiply charged ions present [4]. Due to such advantageous aspect, FCVA is industrial techniques for the deposition of thin materials, especially for the deposition of carbon films, and many works can be found on these films $[5,6]$.

In this paper, we present our results on the deposited DLC coatings for wide range of optical materials prepared by FCVA method. DLC coating were investigated with respect to their mechanical and optical properties, and some conclusions on the influence of the process peculiarities on the coatings properties were drawn.

\section{Experimental}

The DLC films were deposited on the polished, p-type silicon (111) and germanium substrates, soft materials $\left(\mathrm{BaF}_{2}, \mathrm{MgF}_{2}\right)$, glass and polarized polyvinyl chloride (PVC) iodine doped film using filtered cathodic vacuum arc. Technological process is based on the separated arc graphite sputtering from a rotating cylindrical cathode.

Fig. 1 shows the schematics of the experimental system. In this apparatus carbon plasma is generated by pulsed laser initiation to produce an arc discharge (power $25 \mathrm{~kW}$, applied voltage $380 \mathrm{~V}$ ) in a vacuum with a background gas pressure of $10^{-4} \mathrm{~Pa}$ or less. The cathode target consists of carbon (graphite) from which electrons and carbon ions made up of mostly $\mathrm{C}^{+}$are generated. The carbon ions are efficiently introduced into the process chamber via the curved separator under electromagnetic field.

The deposition parameters are listed in Table 1.

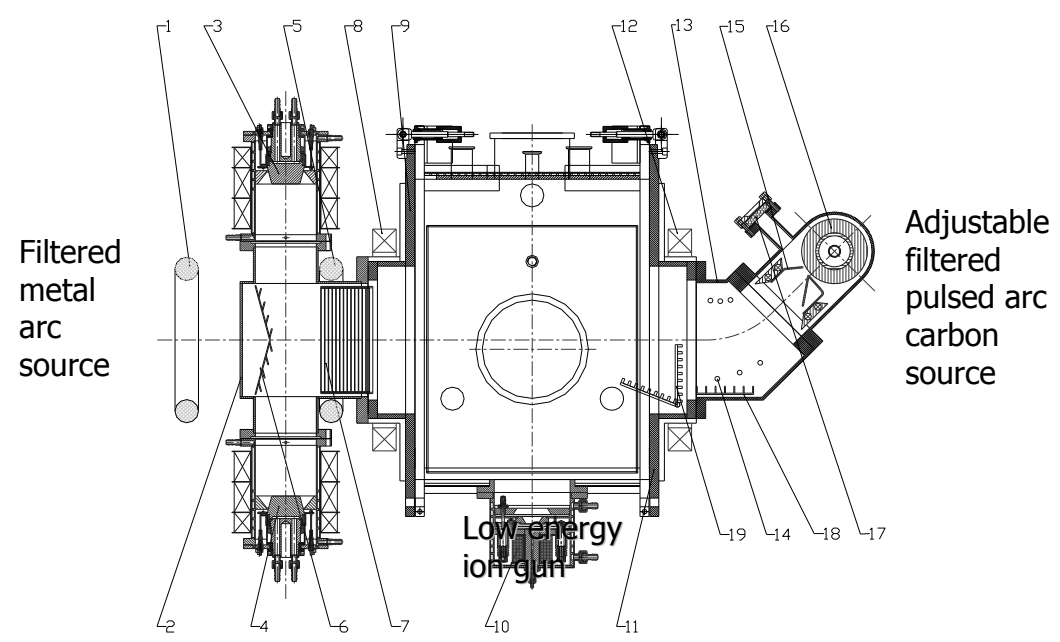

Fig. 1: The scheme of a rig for diamond like carbon coating deposition.

1,5 - solenoid, 2 -camera filter, 3,4 - titanium target, 6,7 - trap particles, 8,12 - solenoids for plasma confinement (Helmholtz coils), 9,11 - water cooling, 10 - ion gun, 13- camera filter, 14 - carbon filters, 15 - anode, 16 - graphite cathode, 17 - window for the laser, 18, 19 filtration system

Table 1: Experimental conditions of DLC coating deposition

\begin{tabular}{ccccccccc}
\hline & \multicolumn{3}{c}{ Argon etching } & \multicolumn{4}{c}{ Carbon deposition } \\
\cline { 2 - 9 } Sam-ple & $\begin{array}{c}\text { Cur- } \\
\text { rent, A }\end{array}$ & $\begin{array}{c}\text { Vol- } \\
\text { tage, V }\end{array}$ & $\begin{array}{c}\text { Flow rate } \\
(\mathrm{sccm})\end{array}$ & $\begin{array}{c}\text { Laser } \\
\text { power, } \\
\mathrm{mJ}\end{array}$ & $\begin{array}{c}\text { Cathode } \\
\text { voltage, V }\end{array}$ & $\begin{array}{c}\text { Frequen } \\
\text { cy, Hz }\end{array}$ & Impulses & $\begin{array}{c}\text { Tempe- } \\
\text { rature, }{ }^{\circ} \mathrm{C}\end{array}$ \\
\hline $\mathrm{Si}$ & 2,5 & 800 & 25 & 30 & $250-280$ & 20 & 222000 & 34 \\
\hline $\mathrm{Ge}$ & 2,5 & 800 & 25 & 30 & $250-280$ & 20 & 222000 & 34 \\
\hline $\mathrm{Glass}$ & - & - & - & 30 & $250-280$ & 20 & 20000 & 35 \\
\hline $\mathrm{BaF} 2$ & - & - & - & 30 & $250-280$ & 20 & 20000 & 35 \\
\hline $\mathrm{MgF} 2$ & - & - & - & 30 & $250-280$ & 20 & 20000 & 35 \\
\hline $\mathrm{PVC}$ & - & - & - & 30 & $250-280$ & 20 & 20000 & 35 \\
\hline
\end{tabular}


The $\mathrm{Si}$ and Ge wafers were cleaned in acetone and distilled water and then pre-etched with argon ion beam before the film growth to remove the native oxide. Glass samples were cleaned in acetone and distilled water. BaF2, MgF2 and PVC are hydrophobic and there are no dust particles on the surfaces of the samples, optically controlled.

Optical properties of deposited diamond-like carbon coatings were measured at PerkinElmer Lambda 950 spectrometer (in the range from 0.2 to 3 microns) and at IR- Fourier spectrometer VERTEX $70 \mathrm{~V}$ (from 3 to 20 microns).

Optical properties and thickness of coatings was defined as the results of multispectral measurements of transmission of a film-substrate system using the quasi-decision selection method for minimization of discrepancy function of the form (2) [7]:

$$
F=\sum_{i=1}^{N}\left[T\left(\lambda_{i}\right)_{\mathrm{exp}}^{2}-T\left(\lambda_{i}\right)_{\mathrm{mod}}^{2}\left(n_{1}, k_{1}, d_{1}\right)\right]^{2}
$$

where: $\mathrm{N}$ - number of radiation wavelengths at which measurements are made; $\mathrm{R}\left(\lambda_{\mathrm{i}}\right)^{2}{ }_{\exp }\left(\mathrm{T}\left(\lambda_{\mathrm{i}}\right)^{2} \exp \right)$, $\mathrm{R}\left(\lambda_{\mathrm{i}}\right)^{2}{ }_{\text {mod }}\left(\mathrm{T}\left(\lambda_{\mathrm{i}}\right)^{2}{ }_{\text {mod }}\right)$, - experimentally measured and model values of reflection (pass) coefficients at $\lambda_{\mathrm{i}}$ wavelength; $\mathrm{n}_{1}, \mathrm{k}_{1}, \mathrm{~d}_{1}$ - coefficients of refraction, absorption and film thickness accordingly.

For the model description of film transmission the matrix method described in [8] was used. It allows taking into account possible deviations from an ideal case, such as inhomogeneity of layers and roughness of transitions between them, existence of "thick" layers.

Minimization of function of the form (1) is a complex optimizing task as discrepancy function can have complex nature with a large number of local minima and can be defined not in all area of search, the number of variables on which minimization is carried out can reach 10 and more, it can be: film thickness, coefficients of model dependence $n_{1}(\lambda)$ (e.g. coefficients of Sellmeier equation), coefficients of model dependence $\mathrm{k}_{1}(\lambda)$.

Special program software [7] providing measurement of thickness and optical properties of diamond like carbon coating was developed with use of visual programming environment LabVIEW 2011 in which use of two algorithms of optimization is realized: method of consecutive square programming [9], and method of differential evolution [10].

Mechanical properties was measured on Nanoindentor Hysitron TI750 UBI with Oliver-Farrah's (ISO 14577) method with use of Berkovich-type indentor, what is a trihedral diamond pyramid with an angle at the vertex about $142^{\circ}$.

\section{Results and discussion}

The DLC coatings deposited by FCVA process were visually smooth and flat. The thickness of the deposited coatings as measured by Nanoindentor Hysitron TI750 UBI. In table 2 are presented the measured results of hardness of samples. The results is demonstrated the increasing of surface hardness due to deposited diamond-like carbon coating.

Table 2: Mechanical characteristics of DLC coatings

\begin{tabular}{|c|c|c|c|c|c|}
\hline $\begin{array}{l}\text { Substrate } \\
\text { material }\end{array}$ & $\begin{array}{l}\text { Coating } \\
\text { thickness, nm }\end{array}$ & $\begin{array}{l}\text { Substrate } \\
\text { material } \\
\text { hardness, GPa }\end{array}$ & $\begin{array}{l}\text { DLC-coating } \\
\text { hardness, GPa }\end{array}$ & $\begin{array}{l}\text { Substrate } \\
\text { elasticity module, } \\
\text { GPa }\end{array}$ & $\begin{array}{l}\text { Strengthened } \\
\text { surface elasticity } \\
\text { module, GPa }\end{array}$ \\
\hline $\mathrm{BaF}_{2}$ & 72 & 1.7 & 4.3 & 66.03 & 90.4 \\
\hline $\mathrm{MgF}_{2}$ & 71 & 7.2 & 14.7 & 136 & 162.4 \\
\hline $\mathrm{Si}$ & 65 & 12.10 & 20.15 & 116,5 & 130.7 \\
\hline $\mathrm{Ge}$ & 101 & 12.10 & 14.36 & - & - \\
\hline Glass & 15 & 8.5 & 12.61 & 88.6 & 125.6 \\
\hline PVC & 15 & - & 1.15 & - & 9.5 \\
\hline
\end{tabular}

The analysis of mechanical properties of the deposited coatings of the considered optical materials deposited on various types of substrates, showed that diamond-like carbon coating deposition conducts to increase of their surface hardness from $18 \%$ for Ge to 2.5 times on a 
substrate made from soft $\mathrm{BaF}_{2}$ with increase of elasticity module of the strengthened surface from 10 to $36 \%$.

Results of spectral transmission characteristics measurements of studied samples are presented in Fig. 2 and Fig. 3. On the basis of the analysis of the received spectral characteristics one can make the conclusion that after strengthening diamond like coating deposition preservation of spectral range of transmission of prototypes in IR range for $\mathrm{BaF}_{2}$ and $\mathrm{MgF}_{2}$ is provided and also some enlightenment for samples from $\mathrm{Ge}$ and $\mathrm{Si}$ is observed.

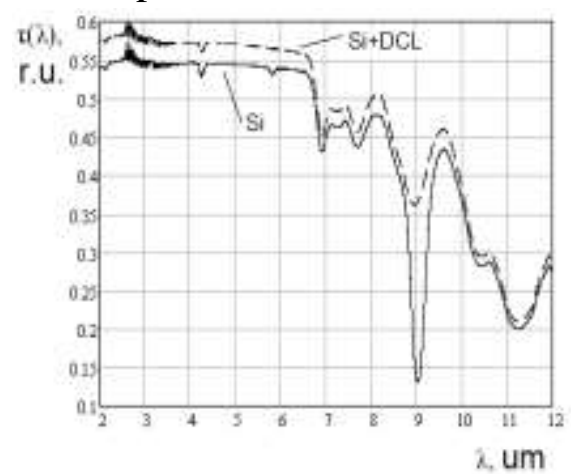

(a)

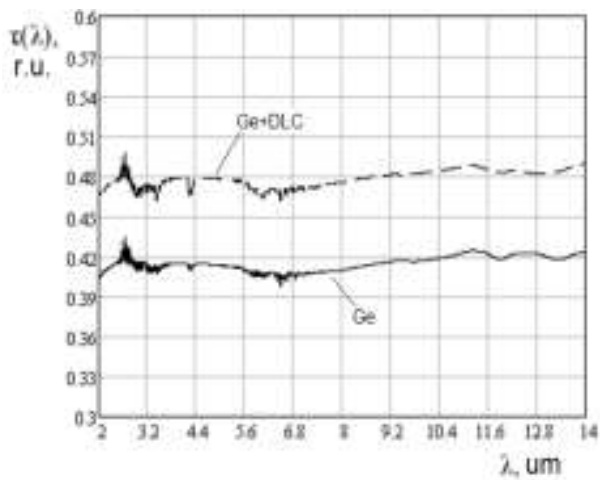

(b)

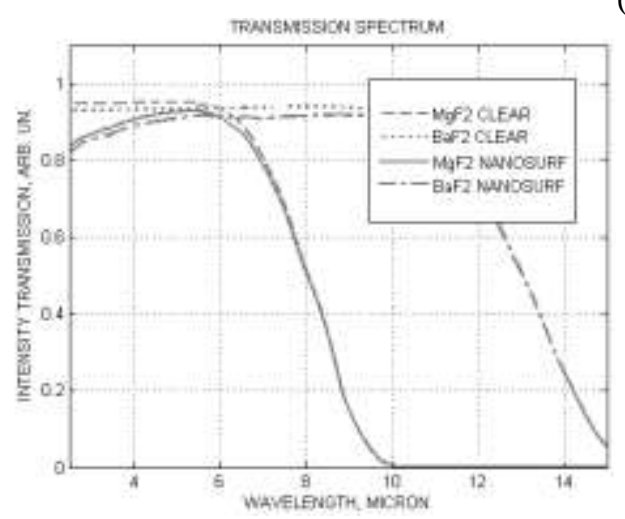

(c)

Fig. 2: Transmission IR range spectrum $\mathrm{Si}(\mathrm{a}), \mathrm{Ge}(\mathrm{b}), \mathrm{MgF} 2$ and $\mathrm{BaF} 2$ (c)

Optical constants of DLC coating on Ge and Si substrates are presented in figure 4.

Optical coefficients of DLC coatings depends on substrates for $\mathrm{Ge}$ and $\mathrm{Si}$ due to different conditions of carbon layer nucleation at deposition process, and as a consequence, different structure of the deposited diamond-like carbon coating.

Surface hardening of optical "soft" materials with preservation of their optical properties can be considered as the important practical result capable to increase considerably operational properties of these materials. At the same time semiconductor materials, as a rule, demand an achievement of essential enlightenment.

Fig. 4 shows optical properties (transmission coefficients) of DLC coating on substrates glass and PVC. For PVC samples transmission coefficients was measured in polarized light (parallel (b) and orthogonal component (c)).

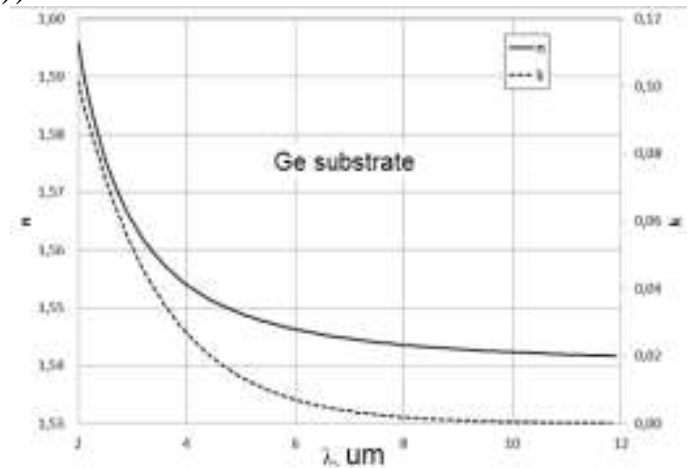

(a) 


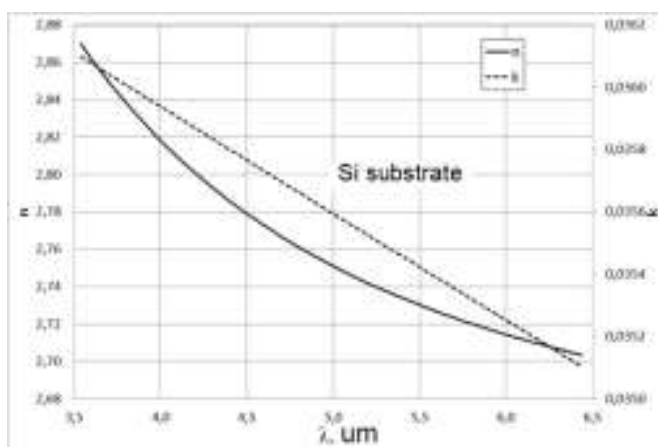

(b)

Fig. 3: Refraction and absorption coefficients of the DLC coating on Ge (a), Si (b)

The analysis of data presented in Fig. 4 and in Table 2 allows to make a conclusion that with developed DLC coating by FCVA deposition on optical materials (glass, optic soft crystals, semiconductors, polymer substrate) with appropriate temperature deposition and properties. DLC coating provide improvement of optical properties optical materials for semiconductors and $\mathrm{MgF}_{2}$ and $\mathrm{BaF}_{2}$ in the IR range, requirement optical characteristics for glass and polarized polyvinyl chloride (PVC) iodine doped film with increasing their surface hardness and wear resistance properties.

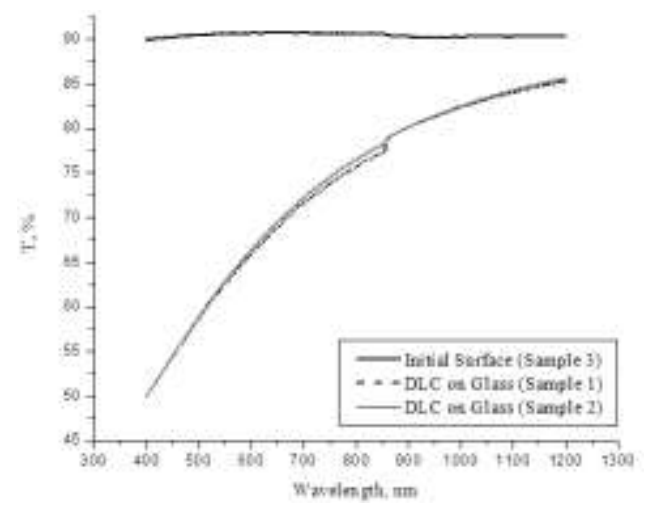

(a)

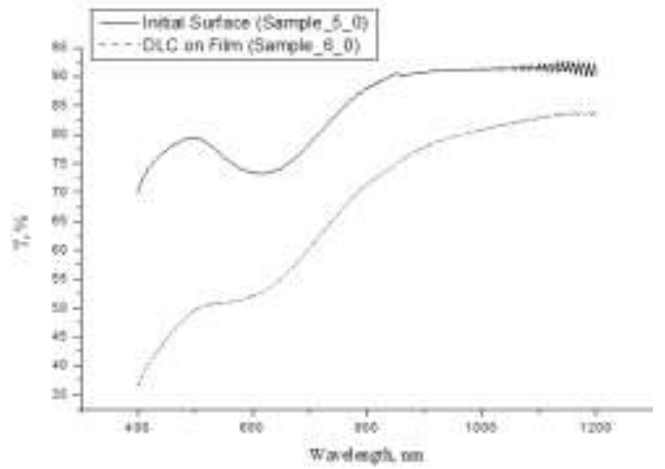

(b)

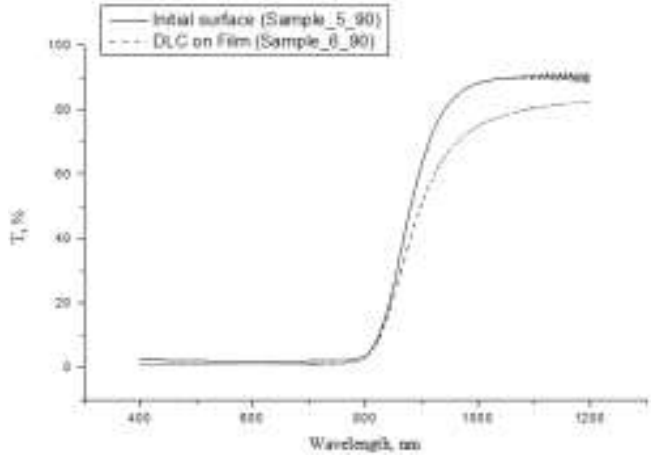

(c)

Fig. 4: Optical properties (transmission coefficient) of DLC coating on glass (a) and PVC with parallel component (b) and orthogonal component (c). 


\section{Conclusions}

Diamond-like carbon coatings deposited on wide range optical materials by filtered cathodic vacuum arc method has been discussed. Experimental studies showed that surface hardening of optical materials operable in IR and visible range by deposition of diamond-like carbon coating on their surface considerably improves mechanical properties of these materials and improves their optical properties. Obviously, developed technology of DLC deposition including antireflection coatings is of great practical interest for industry developers of optic systems for modern thermovision devices working in conditions of aggressive mechanical impacts on optical elements.

\section{Acknowledgements}

The research work was carried out in the Sharing Equipment Center "Educational and engineering center of nanotechnology, nano- and microsystem technique" of Bauman Moscow State Technical University.

This work was supported by the Ministry of Industry and Trade of the Russian Federation under contract No. 12411.1400099.16.007.

\section{References}

[1] M. C. Angus, C. C. Hayman, Science 241, 913 (1988), J. Robertson, Surf. Coat. Technol. 50, (1992), 185.

[2] J. Robertson in: Comprehensive Hard Materials, edited by V.K. Sarin, volume 3, Elsevier Ltd. (2014).

[3] M. Gioti, S. Logothetidis, C. Charitidis, Y. Panayiotatos, I. Varsano: Sensors and Actuators, A: Physical, 99 (1-2), (2002) pp. 35-40.

[4] I.G. Brown: Rev. Sci. Instrum., 1994. 65(10): pp. 3061-3081.

[5] Y. Lifshitz: Diamond Relat. Mater. 8 (1999) 1659.

[6] P.J. Fallon, V.S. Veerasamy, C.A. Davis, J. Robertson, G.A.J. Amaratunga, W.I. Milne: Phys. Rev., B 48 (1993) 4777.

[7] Y. Fedotov, R. Stepanov: Engineering and scientific applications based on technologies National Instruments - 2013. (2013) p. $147-149$.

[8] C. Katsidis, D.I. Siapkas: Applied optics.Vol. 41, N. 19. (2002) p. 3978-3987.

[9] J. Bonnans: Numerical optimization: Theoretical and practical aspects (Springer-Verlag, 2006.

[10] K. Price, R.M. Storn, J.A. Lampinen: Differential Evolution: A Practical Approach to Global Optimization. (Berlin: Springer - Verlag, 2005). 